\title{
Consumer preferences for upcycled ingredients: a case study with biscuits
}

Article

Accepted Version

Creative Commons: Attribution-Noncommercial-No Derivative Works 4.0

Grasso, S. and Asioli, D. ORCID: https://orcid.org/0000-00032274-8450 (2020) Consumer preferences for upcycled ingredients: a case study with biscuits. Food Quality and Preference, 84. 103951. ISSN 0950-3293 doi: https://doi.org/10.1016/j.foodqual.2020.103951 Available at https://centaur.reading.ac.uk/89890/

It is advisable to refer to the publisher's version if you intend to cite from the work. See Guidance on citing.

To link to this article DOI: http://dx.doi.org/10.1016/j.foodqual.2020.103951

Publisher: Elsevier

All outputs in CentAUR are protected by Intellectual Property Rights law, including copyright law. Copyright and IPR is retained by the creators or other copyright holders. Terms and conditions for use of this material are defined in the End User Agreement.

\section{www.reading.ac.uk/centaur}

\section{CentAUR}

Central Archive at the University of Reading 
Reading's research outputs online 


\section{Consumer preferences for upcycled ingredients: a case study with biscuits}

2

3

4

5

6

7

8

9

10

11

12

13

14

15

16

17

18

44

4519

46

47

$48^{20}$

49

5021

51

52

5322

54

55

56

57

5824

59

60

61

62

63

64

65

\section{Simona Grasso ${ }^{1, \mathrm{a}}$ and Daniele Asioli ${ }^{\mathrm{b}}$}

${ }^{a}$ Institute of Food, Nutrition and Health (IFNH),

University of Reading, Reading, United Kingdom.

${ }^{\mathrm{b}}$ Department of Applied Economics and Marketing,

School of Agriculture Policy and Development,

University of Reading, Reading, United Kingdom.

${ }^{1}$ Corresponding author: email address: $\underline{\text { simona.grasso@ucdconnect.ie }}$ 


\section{ABSTRACT}

Nowadays, there is a growing interest to add value to food industry by-products and incorporate them as new ingredients for novel food products. However, there is very little knowledge about consumers' reactions towards novel food products made with upcycled ingredients. This manuscript provides the first critical scientific investigation of UK consumers' preferences for novel food products made with upcycled ingredients using four attributes: price $(£ 0.40 / 300 \mathrm{~g}$ pack or $£ 1.50 / 300$ g pack), flour ("with wheat flour" or "with upcycled sunflower”), protein ("source of protein" or no information) and Carbon Trust label ("with Carbon Trust label" or no label). Using a 33 hypothetical ranking experiment involving biscuits, results showed that consumers prefer biscuits 34 made with conventional (i.e., wheat) flour and tend to reject biscuits made with upcycled sunflower 35 flour. Results suggest there is heterogeneity in consumers' valuation, with three groups identified: 36 the first group with price sensitive consumers and the strongest preferences for low price biscuits, 37 the second group with traditionalist consumers and strongest rejection for upcycled sunflower38 flour, the third group with environmentalist consumers and the strongest preference for biscuits 39 with the Carbon Trust label. Most consumers had not heard of upcycled ingredients before, but 40 they would consider buying foods with upcycled ingredients. These findings provide insights into 41 the psychology of consumers' preferences, which can be used to most effectively communicate the 42 benefits of upcycled ingredients to the public. This will also have important implications for future 43 labelling strategies for policy makers providing valuable insights to upcycled food products' 44 manufacturers.

KEY WORDS: Upcycled ingredients; Sunflower by-product; Sustainable biscuits; Consumers' preferences; Individual differences; Circular economy. 


\section{INTRODUCTION}

51 Every year about $30 \%$ of the total food produced in the world for human consumption is lost or 52 wasted both at food supply chain (i.e., food loss) and consumption levels (i.e., food waste), 53 corresponding to approximately 1.3 billion tonnes (FAO, 2011). In Europe, industrial food loss 54 quantities range between $19 \%$ and $39 \%$ of the total food loss in food supply chains (Stenmarck et 55 al., 2016). In the UK, according to a recent report by the Waste \& Resources Action Programme 56 (WRAP (2017)), in 2015 the manufacturing sector was the main producer of food loss in the supply 57 chain, with 1.85 million tonnes of waste produced (which increased by $9 \%$ compared to the 58 previous 2016 WRAP report). Out of this total amount, almost 1 million tonnes were estimated to 59 be edible parts. Thus, although there is high recognition of the importance of food loss within food 60 supply chains, a large part of research in industrialized countries has focused more on food waste 61 research on the consumer end (Parfitt, Barthel, \& Macnaughton, 2010), while the contribution of 62 the food processing stages on food loss have been overlooked. Fruit and vegetable loss represents 63 the wasting of food commodities, but also includes wasting of important resources such as land, water, fertilisers, chemicals, energy, and labour (Augustin, Sanguansri, Fox, Cobiac, \& Cole, 2020). The food loss produced by the manufacturers from processing raw materials into food are usually referred to as food by-products (Galanakis, 2012). These by-products include both loss from animal processing (i.e., meat, seafood, and dairy) and fruit and vegetable-derived processing (i.e., peels, stems, seeds, bran, residues after extraction of oil or juices, etc.) (Helkar, Sahoo, \& Patil, 2016). Since the fruit and vegetable processing industry is one of the greatest producers of by-products (FAO, 2015; Parfitt et al., 2010), during the last few years, particular attention has been given to the valorization of this by-product category (Galanakis, 2012; Gómez \& Martinez, 2018; Trigo, Alexandre, Saraiva, \& Pintado, 2019). Valorizing fruit and vegetable by-products would make our bio-economy more circular and would help to lower the high environmental impact of by-product disposal (Kroyer, 1995). Considering the vast amount of by-products 
available, even a small increase in their value could have significant economic advantage to food

manufacturers, provided that food supply chains adapt and work towards integration (Garcia-

Garcia, Stone, \& Rahimifard, 2019).

79 Scientists are continuously exploring new ways to add value to food by-products. Examples 80 include extracting and purifying valuable health-promoting compounds from by-products using 81 new technologies (Barba, Zhu, Koubaa, Sant'Ana, \& Orlien, 2016; Galanakis, 2013), exploring the 82 effects of feeding such by-products to animals (Mirzaei-Aghsaghali \& Maheri-Sis, 2008; Molina83 Alcaide \& Yáñez-Ruiz, 2008) or using by-products for energy production (Hagman, Eklund, \& 84 Svensson, 2019; Martin \& Parsapour, 2012). Within valorization, it is believed that the most valuable approach with by-products would be to upcycle them rather than recycling them, which means using them as food, rather than feed or energy (Roth, Jekle, \& Becker, 2019). A similar concept is explained in the Food Recovery Hierarchy of the US Environmental Protection Agency (Bhatt et al., 2018), where energy recovery, composting or incinerating are considered less preferred options to reduce food waste compared to the most preferred options of "source reduction and reuse" and "feed hungry people".

Fruit and vegetable by-products can be processed to become functional and nutritious ingredients that can re-enter the food chain as part of new foods (Trigo et al., 2019). Despite the technological challenges related to the processing, functionality and sensory quality of such ingredients, some upcycled ingredient manufacturers have already launched (or are about to launch) their products into the market. Examples are brewers' spent grains in cereal bars (such as Remashed in the UK and Regrained in the US), coffee grounds in baked goods (Coffee Cherry Company in the US and Kaffe Bueno in Denmark), oil cakes such as rapeseed or sunflower in high-protein flours (Planetarians in the US and NapiFeryn BioTech in Poland) (Fastcompany, 2019; Food Business 
News, 2019; Food Navigator USA, 2018).

In order to successfully market food products with upcycled ingredients it is essential to investigate consumers' preferences and willingness to pay (WTP) towards these novel food products. So far, very little is known about how consumers might perceive foods made with upcycled ingredients. Some of the few available investigations include the research from Bhatt et al. (2018) in the US on "value-added surplus products (VASP)", Aschemann-Witzel and Peschel (2019) in Denmark on potato protein in a mock-up soy-based cocoa drink, and in Italy with two studies by Coderoni and Perito (2020) and Perito, Di Fonzo, Sansone, and Russo (2019) on consumer acceptability of foods with by-products deriving from olive oil production. The concept of foods made with upcycled ingredients is new and in the available literature the names used to refer to these products vary greatly among studies. We will discuss them here in more detail.

Bhatt et al. (2018) referred to foods created from surplus ingredients as "value-added surplus products (VASP)". The authors tried to identify the best term to describe VASP products by asking consumers to rank the appropriateness of nine product labels (i.e., upcycled, reprocessed, reclaimed, upscaled, rescued, up-processed, rescaled, resorted) and found that the word "upcycled" was the most preferred. Then, they investigated whether VASP products were perceived by consumers as having benefits for the individual or for the society, concluding that the VASP foods scored higher as a benefit for society than as an individual. The authors concluded that appropriate product descriptions, labels and benefits could all positively influence consumers' decision-making on this new food category.

Aschemann-Witzel and Peschel (2019) explored how Danish consumers of cocoa drinks react to the use of potato protein, a by-product of potato starch production, in a mock-up soy-based cocoa drink. The authors refer to upcycled ingredients as "waste-to-value" products. They found that consumers did not perceive the new potato protein-based cocoa drink more favourably than the 
conventional version, nor did they consider it better in quality. The authors concluded that brand, design, and information on why a "waste-to-value" ingredient is used could improve attitudes towards the product.

In Italy, Perito et al. (2019) focused on what they called "foods from olive by-products" and assessed consumers' willingness to accept (WTA) them. They found that consumers perceived the use of olive by-products as a new technology to prepare well-known foods. Consumers were concerned about the technology used in the production process, rather than the product itself. The study concluded that information on the characteristics of olive by-products could offset consumer technophobia and the authors recommended suitable marketing campaigns centred on the byproduct benefit to increase consumer WTA the products.

Coderoni and Perito (2020) carried out a web based questionnaire in Italy using the same concept of olive by-product as Perito et al. (2019), testing purchase intentions for what they refer to as "waste-to-value" foods and analysing other drivers such as aversion to new foods or foods processed in new ways. The authors concluded that to deliver new "waste-to-value" products in the market, their health and environmental benefits should be indicated on the label. However, based on findings from Vega-Zamora, Torres-Ruiz, and Parras-Rosa (2019) and Agovino, Cerciello, and Gatto (2018), they suggest that attention must be paid to the messages conveyed as failure to notice or interpret labels could hinder the final market uptake.

Consumers' acceptability provides important information for producers and marketers when developing new food products, however simply asking consumers for their acceptability without considering price may not provide the needed practical information (Asioli et al., 2017). Thus the inclusion of price as an attribute to estimate consumers' WTP in monetary terms is relevant for several reasons (Jaeger, 2006). Firstly, a large number of studies indicate that price is one of the most relevant factors that affect consumer choices (Asioli, Næs, Granli, \& Lengard Almli, 2014; 
Lusk \& Briggeman, 2009; Steenhuis, Waterlander, \& de Mul, 2011). Secondly, for new food products that are not yet in the market and for which there are no market data available (i.e.,

scanner data), an estimation of consumers' WTP could help industry to suggest retail prices when launching new products (Lusk \& Shogren, 2007; Shogren, 2011). Thirdly, an estimation of new food products' prices is useful for industry to compare with production costs, conduct a costs/benefits analysis and evaluate the economical/business sustainability of the new products (Lusk \& Shogren, 2007). However, to the best of our knowledge, no study has directly investigated consumers' preferences and WTP in monetary terms and individual differences for food products containing upcycled ingredients. Due to the new nature of upcycled ingredients, it would be valuable to gather insights on how to best introduce this new upcycled food category to the market and how to communicate the nutritional and environmental advantages of foods made with byproducts to consumers through appropriate labelling strategies. This study aimed at understanding the most preferred attribute composition for upcycled foods using the attributes price (low or high), type of flour (conventional or upcycled), protein content ("source of protein" or no information) and Carbon Trust label ("with Carbon Trust label" or no label).

A ranking experiment was used to investigate UK consumers' preferences for hypothetical biscuits made with defatted sunflower cake flour. The upcycled sunflower flour was chosen as an ingredient for this study because the company Planetarians ${ }^{2}$ successfully manufactured it from sunflower cake, the residue left after sunflower oil extraction. Through a steam flashing and extrusion process, the sunflower cake is transformed into a high protein food grade ingredient (Manchuliantsau \& Tkacheva, 2019). This protein-rich ingredient could be potentially used by the food industry in a variety of applications, such as bakery, pasta and meat products. This ingredient

\footnotetext{
${ }^{2}$ See details: https://www.planetarians.com/
} 
was also recently used in baked goods with promising results (Grasso, Liu, \& Methven, 2020;

Grasso, Omoarukhe, Wen, Papoutsis, \& Methven, 2019). Biscuits were chosen as a base food for this study due to their popularity and appeal amongst consumers, in addition to being ready to eat, affordable, having a long shelf life and a wide range of tastes (Turksoy \& Özkaya, 2011).

\section{MATERIALS AND METHODS}

\subsection{Experimental design}

In the online ranking experiment four attributes were used to describe the different types of biscuits: "price", "flour", "protein" and "Carbon Trust label" (Table 1). In terms of the attribute "price", two price levels were specified to approximately reflect the upper and lower market prices of a typical $300 \mathrm{~g}$ pack of biscuits in UK shops (£0.40/300 g pack and $£ 1.50 / 300 \mathrm{~g}$ pack). Price was chosen as an attribute because, as indicated in the introduction, it is one of the most relevant factors that affect consumer choices (Lusk \& Briggeman, 2009). For the attribute "flour", two levels were specified: the most conventional type of flour used to make biscuits (i.e. "with wheat flour") or the innovative flour (i.e. "with upcycled sunflower”). This attribute was used to test consumers' WTP for new foods with upcycled ingredients. The attribute "protein" was included with two levels: "source of protein" or no information about this was reported. "Source of protein" refers to the nutrition claim as per European Food Safety Authority wording (EFSA, 2012), indicating that at least $12 \%$ of the energy value of the food is provided by protein. Protein content in food products overall has a positive consumer perception, especially if the protein is of plant-origin (Banovic et al., 2018). Finally, we included information about the environmental impact of biscuit production because it has been shown that sustainability information may affect consumers' WTP (Reimers \& Hoffmann, 2019). We used the "Carbon Trust label" referring to the environmental impact of food production, transportation and use of the food products in terms of $\mathrm{CO}_{2}$ emissions. Thus, two levels 
${ }_{4} 197$ of Carbon Trust label were used: "with Carbon Trust label" or no label was reported. 


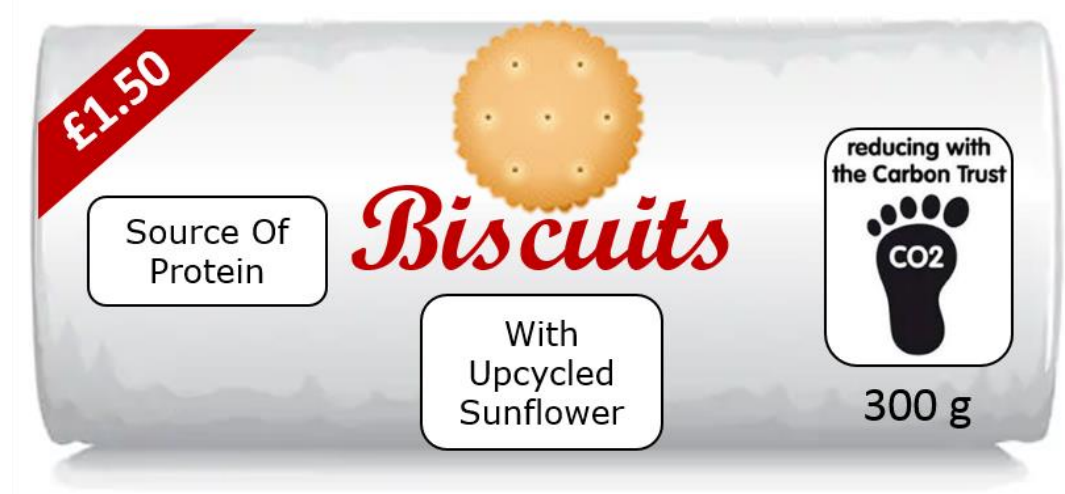

Fig.1 - Example of mock-up product image created for the study.

The randomisation was conducted within each block of eight choice sets. The ranking experiment was introduced with an explanation and description of the attributes and levels. Participants were presented with biscuit packs and asked to rank them from the most preferred to the least preferred option. Before starting the ranking tasks, respondents were asked to read a cheap talk script as an attempt to mitigate possible hypothetical bias that typically affects WTP estimates in stated preference studies (Cummings \& Taylor, 1999).

To ease the cognitive burden of the participants, this ranking was conducted similarly to $\emptyset_{\mathrm{v} r u m}$ Alfnes, Almli, and Rickertsen (2012) as a series of choices over seven screens. On the first screen all eight biscuit packs were shown and the participants were asked to mark their four most preferred biscuits. The six next screens proceeded as follows. On screen (2) the four selected biscuit packs from screen (1) were shown and the participants were asked to select the most preferred biscuits among these (i.e., their top-ranked biscuit pack). On screen (3) the three remaining biscuit packs from screen (2) were shown and the participants were asked to select the most preferred biscuit among these. On screen (4) the two remaining biscuits from screen (3) were shown and the participants were asked to select the most preferred option among these. Screens 
(5)-(7) proceeded in the same way as screens (2)-(4) but now for the four least preferred biscuit packs.

\subsection{Data}

The data used in this study are drawn from an online survey composed of a ranking experiment followed by a questionnaire conducted during summer 2019 involving 106 consumers in the UK using the online platform Qualtrics LLC (Provo, US). Consumers where randomly recruited by Qualtrics using sampling quotas in terms of age and gender. Consumers were informed about the 
opportunity to participate in a survey on consumers' evaluation of biscuits. Only consumers who

were at least 18 years old, who bought and ate biscuits and did not follow gluten-free diets were

The socio demographic characteristics of the sample are presented in Table 2. Given the quota sampling, the final sample was composed of 50\% females and 50\% males, which is very similar to the most recent UK population census data, composed of $50.64 \%$ females and $49.36 \%$ males (Office for National Statistics, 2019). In terms of age, 30.19\% of participants were 18-32 years old, $19.81 \%$ were $33-46$ years old, $32.80 \%$ were $47-61$ years old and $17.92 \%$ were $62-75$ years old. These age ranges are similar to the UK census population, respectively $27.30 \%, 25.09 \%, 27.99 \%$ and $16.63 \%$ (Office for National Statistics, 2019). One or two people composed more than $50 \%$ of households and $2 / 3$ of the respondents did not have children under 18 years old. Almost $50 \%$ of the sample had annual income before tax less than $£ 30,000$ while more than $50 \%$ of the respondents were public or private sector employees. In terms of education, almost $85 \%$ of the consumers had at least an undergraduate university degree.

Table 2 - Socio-demographic characteristics of the UK consumers in this study.

\begin{tabular}{lc}
\hline SOCIO-DEMOGRAPHICS: Number $(\boldsymbol{\%})$ & $\begin{array}{c}\text { SAMPLE } \\
\text { (N=106) }\end{array}$ \\
\hline Gender & \\
$\quad$ Male & $53(50.00 \%)$ \\
$\quad$ Female & $53(50.00 \%)$ \\
\hline Age & \\
$18-32$ & $32(30.19 \%)$ \\
$33-46$ & $21(19.81 \%)$ \\
$47-61$ & $34(32.80 \%)$ \\
$62-75$ & $19(17.92 \%)$ \\
\hline
\end{tabular}




\begin{tabular}{|c|c|}
\hline \multicolumn{2}{|l|}{ Household size ( $\mathrm{n}^{\circ}$ members) } \\
\hline One & $10(9.73 \%)$ \\
\hline Two & $47(44.34 \%)$ \\
\hline Three & $20(18.87 \%)$ \\
\hline Four & $22(20.75 \%)$ \\
\hline Five+ & $7(6.60 \%)$ \\
\hline \multicolumn{2}{|l|}{ Number of children under 18} \\
\hline No children & $67(63.21 \%)$ \\
\hline Children & $39(37.69 \%)$ \\
\hline \multicolumn{2}{|l|}{ Annual household income before taxes } \\
\hline Less than $£ 10,000$ & $10(9.43 \%)$ \\
\hline$£ 10,000$ to $£ 19,999$ & $13(12.26 \%)$ \\
\hline$£ 20,000$ to $£ 29,999$ & $23(21.70 \%)$ \\
\hline$£ 30,000$ to $£ 39,999$ & $18(16.98 \%)$ \\
\hline$£ 40,000$ to $£ 49,999$ & $13(12.26 \%)$ \\
\hline$£ 50,000$ to $£ 59,999$ & $6(5.66 \%)$ \\
\hline$£ 60,000$ to $£ 69,999$ & $9(8.49 \%)$ \\
\hline$£ 70,000$ to $£ 79,999$ & $4(3.77 \%)$ \\
\hline$£ 80,000$ to $£ 89,999$ & $2(1.89 \%)$ \\
\hline$£ 90,000$ to $£ 99,999$ & $1(0.94 \%)$ \\
\hline$£ 100,000$ to $£ 149,999$ & $3(2.83 \%)$ \\
\hline$£ 150,000$ or more & $1(0.94 \%)$ \\
\hline I do not want to declare/I do not know & $3(2.83 \%)$ \\
\hline \multicolumn{2}{|l|}{ Employment } \\
\hline Student & $7(6.60 \%)$ \\
\hline Independent worker & $5(4.72 \%)$ \\
\hline Private-sector worker & $34(32.08 \%)$ \\
\hline Public-sector worker & $23(21.70 \%)$ \\
\hline Retired & $17(16.04 \%)$ \\
\hline Unemployed & $8(7.55 \%)$ \\
\hline Not seeking work & $11(10.38 \%)$ \\
\hline Other work & $1(0.94)$ \\
\hline \multicolumn{2}{|l|}{ Education } \\
\hline Secondary school (e.g. GCSE) & $29(27.36 \%)$ \\
\hline Sixth form College qualification (e.g. A level, BTEC) & $40(37.74 \%)$ \\
\hline Undergraduate University Degree (e.g. $B A, B S c)$ & $21(19.81 \%)$ \\
\hline Postgraduate University Degree (e.g. Masters, PGCE) & $9(8.49 \%)$ \\
\hline Postgraduate University Degree (PhD) & $5(4.72 \%)$ \\
\hline Other & $2(1.89 \%)$ \\
\hline
\end{tabular}

9266

50

51

\subsection{Econometric analysis}

Ranking data are analysed within the utility framework by so-called discrete choice models (DCMs) (Hensher, Rose, \& Greene, 2005; Louviere, Hensher, \& Swait, 2000; Train, 2009). DCMs are based on modelling "Utility", which is the net benefit a consumer obtains from selecting a specific product in a choice situation, as a function of the design attributes. The utility of a product 
${ }_{4}^{3} 272 j$ for individual $n$ in a choice occasion $t$ (choice set) is written:

5

6273

7

${ }^{8} 274$

$$
U_{n j t}=\beta_{n}^{\prime} \mathrm{x}_{j t}+\varepsilon_{n j t}
$$

where $\beta_{n}$ is a vector of individual-specific parameters accounting for preference heterogeneity, $x_{j t}$ is a vector of design attributes, and $\varepsilon_{n j t}$ is a random error term. Under the assumption that the random errors follow a so-called extreme value distribution (Train, 2009) and are independent and identically distributed (i.i.d) the choice probability for product $j$ and choice set $t$ given the parameter $\beta_{n}$ has a simple form:

$$
P_{n j t}=\frac{\exp \left(\boldsymbol{\beta}_{n}^{\prime} \mathbf{x}_{j t}\right)}{\sum_{i=1}^{J_{t}} \exp \left(\boldsymbol{\beta}_{n}^{\prime} \mathbf{x}_{i t}\right)}
$$

where $J_{t}$ is the number of products in choice set $t$.

Among the different DCMs we focused on two of the most applied choice models: the Mixed Logit (ML) model to investigate the pooled sample and the Latent Class Logit (LCL) model to investigate consumers' heterogeneity (Greene \& Hensher, 2003; Train, 2009). ML models are widely applied due to their flexibility and because they allow models that may better match realworld situations (Train, 2009). This flexibility comes from the fact that one may freely include random parameters of any distribution and also correlations between random factors. Thus, in the main specification of the model the design attributes for "flour" (i.e., FLOUR), "protein" (i.e., PROTEIN), “Carbon Trust label” (i.e., CARBON) and "price” (i.e., PRICE) were included. The utility ML model for biscuits $j$ for individual $i$ in choice occasion $t$ is written:

$$
U_{i j t}=\beta_{1 i} \mathrm{FLOUR}_{i j t}+\beta_{2 i} \mathrm{PROTEIN}_{i j t}+\beta_{3 i} \mathrm{CARBON}_{i j t}+\beta_{4 i} \mathrm{PRICE}_{i j t}+\varepsilon_{i j t}
$$


The ML model used here assumes random parameters with normal distributions for all design attributes. These random coefficients are further assumed to be independent. This model provides estimates of the mean and the standard deviation of the random conjoint parameters. The ML model was estimated using the module mixlogit, to obtain the regression coefficients, and the module wtp to obtain the corresponding WTP in monetary terms (i.e., £) (Hole, 2007) run in STATA 15.1 software (StataCorp LP, College Station, US). We run different ML models using different number of draws both with correlated and not correlated variables. Based on LL, AIC and BIC parameters the best model was two thousand Halton draws with no correlated variables used in the simulations. More details on estimation of ML models are found in Train (2009) and Hole (2007).

Next, in order to investigate if consumers' socio-demographics characteristics and consumers' aversion towards new food products have an effect on consumers' preferences for biscuits, starting from the base model (3) a ML including interactions with socio-demographics (i.e., age, gender and education) and FNS (Cronbach alpha: 0.901) was performed. A similar approach was used by Asioli, Næs, Øvrum, and Almli (2016).

Thus, in the model we interacted design attributes for "flour" (i.e., FLOUR), "protein" (i.e., PROTEIN), "Carbon Trust label" (i.e., CARBON) and "price" (i.e., PRICE) with the sociodemographics characteristics such as age (i.e., AGE), gender (i.e., GENDER) and education (i.e., EDUCATION). In addition, we interacted for "flour" the consumers' aversion towards new food products (i.e., FNS). The utility ML model for biscuits $j$ for individual $i$ in choice occasion $t$ is written:

$U_{i j t}=\beta_{1 i}$ FLOUR $_{i j t}+\beta_{2 i}$ PROTEIN $_{i j t}+\beta_{3 i}$ CARBON $_{i j t}+\beta_{4 i}$ PRICE $_{i j t}+\beta_{5 i}(F L O U R * A G E)_{i j t}+\beta_{6 i}$ 


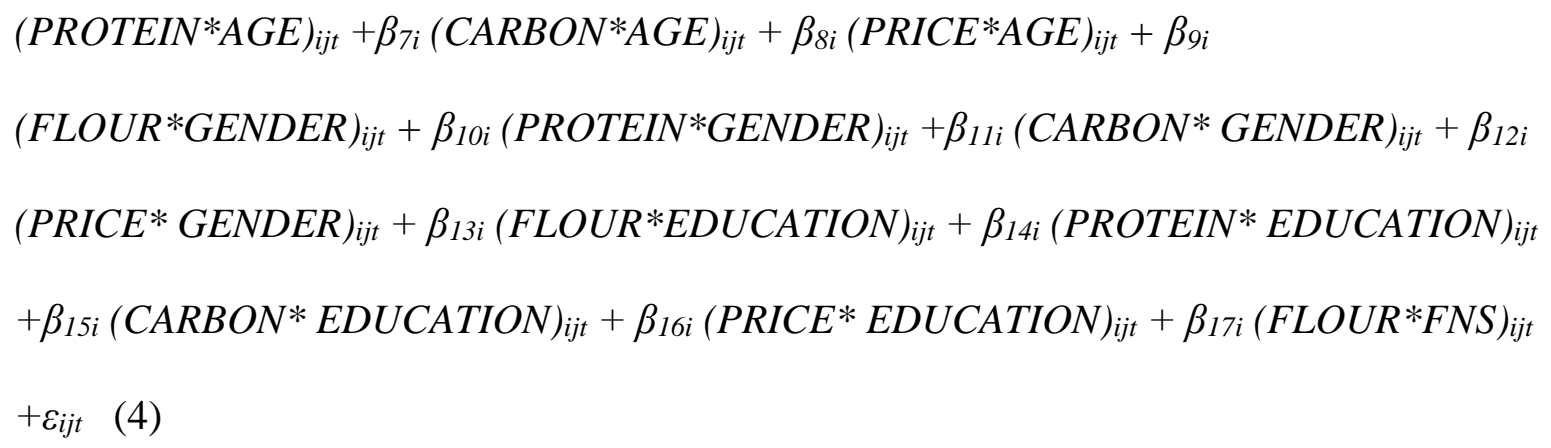

Next, to investigate consumers' heterogeneity, the LCL model was used. The LCL model assumes constant model parameters within each group and captures consumer heterogeneity assuming a mixing distribution for the groups (Greene \& Hensher, 2003; Hess, Ben-Akiva, Gopinath, \& Walker, 2011). The LCL model assumes that the consumer group can be split in subgroups with a constant $\beta$ vector in each group (Greene \& Hensher, 2003). The choice probability that an individual of class $s$ chooses alternative $j$ from a particular set constituted of $J_{t}$ alternatives, is expressed as:

$$
P_{j / s}=\frac{\exp \left(\boldsymbol{\beta}_{s}^{\prime} \mathbf{x}_{j t}\right)}{\sum_{i=1}^{J_{t}} \exp \left(\boldsymbol{\beta}_{s}^{\prime} \mathbf{x}_{i t}\right)}
$$

where $s=1, \ldots S$ represents the number of classes and $\beta$ 's is the fixed (constant) parameter vector associated with class $s$. In order to establish the likelihood, these choice probabilities have to be multiplied over the choice sets and finally combined over all individuals. To estimate the LCL model it is possible to use the Expectation - Maximization (EM) algorithm which allows for a good numerical stability and good performance in terms of run time (Bhat, 1997; Pacifico \& Yoo, 2013; Train, 2008). One of the main issues in the LCL model is the choice of $S$, which is the number of latent classes. Given the fact that $S$ is not a parameter, it is not possible to test it directly (Shen, 2009). Louviere et al. (2000) suggested a number of methods to guide the model selection. 
Specifically, they suggested that the model that minimizes AIC, BIC and CAIC should be preferred

(see for more details, Louviere et al. (2000). In this study, the Latent Class Logit (LCL) model used will include main effects in order to calculate the class parameters $\beta_{\mathrm{s}}$. The main results from the method are the subgroups, the regression parameter within each group and indications of how well each consumer fits into the different subgroups. The method is invariant to the relative scale of the input variables. The LCL model was estimated using the modules lclogit2, lclogitml2, lclogitwtp and lclogitpr2 (Yoo, 2019) run in STATA 15.1 software (StataCorp LP, College Station, US).

\section{RESULTS}

\subsection{Questionnaire results on upcycled ingredient knowledge}

The majority of consumers (85\%) had not heard of the term "upcycled" in relation to a food ingredient before this study. The remaining $15 \%$ of consumers who had heard of upcycled ingredients before the study, had on average a midpoint self-reported knowledge of 3.7 in the 1-7 scale from very low to very high knowledge. The majority of consumers (85\%) would consider buying foods with upcycled ingredients. Consumers were asked why they would (or would not) consider buying foods with upcycled ingredients. For consumers that would consider buying foods with upcycled ingredients, the three most chosen reasons were "because they would be good for the environment" (49\%), "because I would contribute to food waste reduction" (47\%), "because I would like to know what they taste like out of curiosity" (46\%). The least popular answers for consumers that would consider buying foods with upcycled ingredients were "because they would be cheaper than conventional foods" (21\%) and "because they would be healthier than conventional foods" $(25 \%)$. On the other hand, consumers who would not consider buying foods with upcycled ingredients, selected as the main reason for their choice "I have a feeling they would not taste nice" (8\%), followed by "I am not interested in their health benefits" and "they are waste 
products and I would not like to have them in new foods" (5\%). Finally, "they would be more expensive than conventional foods" and "I am not interested in their environmental benefits" were

\subsection{Estimation results from Mixed Logit (ML) Model}

The ML model was estimated in three steps. Firstly, we estimated the regression coefficients of ML model using the command mixlogit (Hole, 2007) run in STATA 15.1 software (StataCorp LP, College Station, US). The results from the estimation of the regression coefficients of the ML model using equation (3) are shown in Table 3. Specifically, in Table 3 the regression coefficients of "price" "flour", "protein" and "Carbon" are reported, as well as the corresponding standard errors and significances for the design attributes. On average, consumers preferred biscuits of a low price, produced with conventional wheat flour and with the labelling information "source of protein" and Carbon Trust. Looking specifically at the coefficients for the design attributes, price had the highest magnitude suggesting that this attribute was the one that mostly affected consumers' preferences. The second most important attribute that influenced consumers' preferences was the Carbon Trust label as, on average, consumers preferred biscuits with the Carbon Trust label information. The third most important attribute that affected consumers' preferences was the information on protein content, with consumers on average preferring biscuits with the information "source of protein". Finally, the least important attribute that influenced consumers' preferences was the type of flour, with the data showing that on average consumers preferred biscuits with conventional wheat flour.

It is interesting to note all the design attributes have significant SDs indicating that there were large individual differences in preferences for the design variables with particular reference to "price", "flour" and "Carbon". 
Table 3 - Estimated parameters for Mixed Logit (ML) model with design attributes' main effects.

\begin{tabular}{|c|c|c|c|c|c|c|}
\hline \multirow{2}{*}{ ATTRIBUTE } & \multicolumn{3}{|c|}{ Mixed Logit (ML) Model } & \multicolumn{3}{|c|}{ SD } \\
\hline & Coefficient & $\mathbf{S E}$ & P-value & Coefficient & SE & P-value \\
\hline Price & -3.25 & 0.40 & 0.00 & 2.89 & 0.41 & 0.00 \\
\hline Flour & -0.72 & 0.23 & 0.00 & 1.93 & 0.25 & 0.00 \\
\hline Protein & 0.90 & 0.17 & 0.00 & 1.21 & 0.19 & 0.00 \\
\hline Carbon & 1.66 & 0.24 & 0.00 & 1.81 & 0.27 & 0.00 \\
\hline \multicolumn{7}{|c|}{ MODEL PARAMETERS } \\
\hline LL & \multicolumn{6}{|c|}{-878.36} \\
\hline AIC & \multicolumn{6}{|c|}{1772.72} \\
\hline $\mathrm{BIC}$ & \multicolumn{6}{|c|}{1822.47} \\
\hline
\end{tabular}

Secondly, based on the ML model presented above and on Table 3, we calculated the consumers' WTP for the attributes "flour", "protein" and "Carbon" (Table 4) using the command wtp (Hole, 2007) run in STATA 15.1 software (StataCorp LP, College Station, US). Table 4 displays the same information reported in Table 3, but expressed in monetary terms, using the marginal WTP. This is the ratio of the coefficient of an attribute ("flour", "protein" or "Carbon") divided by the coefficient for price (-1). In line with the results from Table 3, consumers were willing to pay a lower price for biscuits made with upcycled flour (i.e., $-£ 0.22 /$ pack), and a higher price for biscuits with both the "source of protein" nutrition claim (i.e., $+£ 0.28 /$ pack) and the Carbon Trust label (i.e., $+£ 0.51 /$ pack).

Table 4 - Estimated Willingness to Pay in Preference Space.

\begin{tabular}{cc}
\hline ATTRIBUTE & WTP $(\mathfrak{f} / \mathbf{3 0 0 g r})$ \\
\hline Flour & -0.22
\end{tabular}


Lastly, we investigated the effect of socio-demographics (i.e., age, gender and education) and

Table 5 - Estimated parameters for Mixed Logit (ML) model with design attributes' main effects and interactions with the age, gender, education and the interaction of "flour" with consumers' aversion towards new food products (FNS).

\begin{tabular}{cccc}
\hline ATTRIBUTE & \multicolumn{3}{c}{ Mixed Logit (ML) Model } \\
\cline { 2 - 4 } & Coefficient & SE & P value \\
\hline Flour & 0.69 & 1.09 & 0.53 \\
Protein & 1.46 & 0.63 & 0.02 \\
Carbon & 1.86 & 0.81 & 0.02 \\
Price & -3.05 & 1.16 & 0.01
\end{tabular}




\subsection{Estimation results from Latent Class Logit (LCL) with design attributes' main effects.}

The final stage of the study was to estimate the LCL model in two steps. Firstly, we estimated the regression coefficients for each design attributes of LCL model for the different consumers' segments using the command lclogit2 (Yoo, 2019) run in STATA 15.1 software (StataCorp LP, College Station, US). Based on the BIC parameter (see for details Yoo (2019)), the optimal number of groups for the LCL model was found to be three. The BIC value was 1875.93 with two groups ${ }^{3}$. This value reduced for three groups (1861.63) and raising it to four groups resulted in numerical

\footnotetext{
3 The 2-cluster solution was composed by group 1 ( $\mathrm{N}=41$ consumers) and group 2 ( $\mathrm{N}=65$ consumers) as following, (i.e., attribute and regression coefficient):

- Group 1: Price (-12.79), Flour (-0.38); Protein (0.57) Carbon (1.13);

- Group 2: Price (-0.67), Flour (-0.37); Protein (0.48) Carbon (0.73).
} 
convergence problems. Therefore, a three-group solution was considered. The results of the LCL

model with the three-group solution are reported in Table 6 showing two large and one small

groups. Specifically, in Table 6 the regression coefficients of "flour", "protein", "Carbon" and "price" are reported as well as the corresponding standard errors and significances for the design attributes. In group 1 (52 consumers) consumers had the strongest rejection for the upcycled sunflower flour (i.e., "traditionalist consumers") while in group 2 (41 consumers) consumers had strong preferences for low price biscuits (i.e., "price-sensitive consumers"). The p-value for price in group 2 is due to the substantial amount of statistical noise at the point of estimate. Finally, in group 3 (13 consumers) consumers had strong preferences for biscuits with the Carbon Trust label (i.e., "environmentalist consumers"). The main difference among the three groups was therefore the difference in preference for price and the Carbon Trust label.

Table 6 - Estimated Regression Coefficient from Latent Class Logit (LCL) Model.

\begin{tabular}{|c|c|c|c|c|c|c|c|c|c|}
\hline \multirow[t]{2}{*}{ ATTRIBUTE } & \multicolumn{3}{|c|}{$\begin{array}{c}\text { GROUP 1 } \\
\text { "Traditionalists" }\end{array}$} & \multicolumn{3}{|c|}{$\begin{array}{c}\text { GROUP 2 } \\
\text { "Price sensitive" }\end{array}$} & $\begin{array}{r}\text { Gr } \\
\text { "Envirs }\end{array}$ & $\begin{array}{l}\text { OUP } 3 \\
\text { iment }\end{array}$ & ist" \\
\hline & Coefficient & $\mathbf{S E}$ & P-value & Coefficient & $\mathbf{S E}$ & P-value & Coefficient & SE & P-value \\
\hline Price & -0.60 & 0.13 & 0.00 & -7.17 & 5.63 & 0.20 & -1.42 & 0.40 & 0.00 \\
\hline Flour & -0.46 & 0.14 & 0.00 & -0.37 & 0.17 & 0.03 & -0.13 & 0.40 & 0.77 \\
\hline Protein & 0.50 & 0.13 & 0.00 & 0.57 & 0.15 & 0.00 & 0.81 & 0.36 & 0.03 \\
\hline Carbon & 0.38 & 0.14 & 0.01 & 1.14 & 0.17 & 0.00 & 5.30 & 1.84 & 0.00 \\
\hline
\end{tabular}

Secondly, based on the LCL model presented above and in Table 6, for each consumers' group we estimated the consumers' WTP for "flour", "protein" and "Carbon". We used the command lclogitwtp (Yoo, 2019) in STATA 15.1 software (StataCorp LP, College Station, US) which calculates the ratio of the coefficient of an attribute ("flour, "protein" or "Carbon") divided by the 
coefficient for price (-1). Results are shown in Table 7. Consumers' WTP for a $300 \mathrm{~g}$ pack of

\section{DISCUSSION \& CONCLUSIONS}

Table 7 - Estimated Willingness to Pay in Preference Space ( $(\mathfrak{3} / 300 \mathrm{gr})$.

\begin{tabular}{|c|c|c|c|c|c|c|c|c|c|}
\hline \multirow[t]{2}{*}{ ATTRIBUTE } & \multicolumn{3}{|c|}{$\begin{array}{c}\text { GROUP 1 } \\
\text { "Traditionalist" } \\
(\mathbf{N = 5 2})\end{array}$} & \multicolumn{3}{|c|}{$\begin{array}{c}\text { GROUP } 2 \\
\text { "Price sensitive" } \\
(\mathbf{N}=\mathbf{4 1})\end{array}$} & \multicolumn{3}{|c|}{$\begin{array}{c}\text { GROUP 3 } \\
\text { "Environmentalist" } \\
(\mathbf{N}=13)\end{array}$} \\
\hline & $\underset{\text { (£/300gr) }}{\text { WTP }}$ & SE & P-value & $\underset{(\mathfrak{f} / \mathbf{3 0 0 g r})}{\text { WTP }}$ & SE & P-value & $\underset{(\mathfrak{f} / \mathbf{3 0 0 g r})}{\text { WTP }}$ & SE & P-value \\
\hline Flour & -0.77 & 0.28 & 0.01 & -0.05 & 0.50 & 0.30 & -0.09 & 0.32 & 0.78 \\
\hline Protein & 0.82 & 0.27 & 0.00 & 0.08 & 0.07 & 0.23 & 0.57 & 0.27 & 0.04 \\
\hline Carbon & 0.62 & 0.06 & 0.02 & 0.16 & 0.13 & 0.21 & 3.71 & 1.41 & 0.01 \\
\hline
\end{tabular}

This study aimed to explore consumers' preferences, WTP and heterogeneity for biscuits made with upcycled ingredients and test the use of the "source of protein" claim and Carbon Trust label 
on the pack. We will discuss here how the results from this study advance theory, add to other

studies on upcycled ingredients and provide useful managerial insights into the new area of foods

made with upcycled ingredients.

Results from the questionnaire revealed very poor consumers' knowledge of upcycled ingredients with only $15 \%$ of consumers claiming to have heard of foods with upcycled ingredients before taking part in the study. These results suggest that, although foods with upcycled ingredients can be manufactured (Grasso et al., 2020; Grasso et al., 2019; Spinelli, Padalino, Costa, Del Nobile, \& Conte, 2019), the concept of upcycled ingredients and related benefits might be too novel for consumers and therefore suitable information campaigns should be designed to address this in the UK. More positive results on consumer knowledge of upcycled ingredients were obtained in Italy by Coderoni and Perito (2020). In their study, 61\% of respondents declared to have heard about waste to value foods (and they also knew what the term meant), $20 \%$ had heard about those products (but did not know what they meant) and finally $19 \%$ did not know about the existence of waste to value foods. These different results might be linked to country-specific differences or to the different methods used to gather the data.

Despite the low knowledge, the majority of consumers (85\%) would consider buying foods with upcycled ingredients. This is an important outcome, since the concept of upcycled ingredient overall was not rejected. Coderoni and Perito (2020) also reported positive findings in Italy, with $56 \%$ of respondents in their study claiming that they would buy a food product made with wastes/by-products. The percentage rose to $69 \%$ if the food made with wastes/by-products also reduced the environmental impact of production.

Looking at the reasons why consumers would consider buying foods with upcycled ingredients, it seems that environmental and food waste prevention were the most important factors, followed by curiosity, while the nutritional benefit did not seem to be considered as important for consumers. 
The relationship between food consumption, food waste and the environment has received a lot of

attention by the UK media and retailers in recent times (BBC, 2019; SkyNews, 2019) and consumers might have been favourably influenced by this communication. Future marketing strategies and labelling information should consider these factors to maximise the reach of foods with upcycled ingredients. Coderoni and Perito (2020) found that Italian respondents in their study were also more likely to buy waste-to-value foods if they thought that this could provide health benefits and a lower environmental impact.

Results from the FNS indicate that upcycled ingredients were not significantly linked to food neophobia. This is a positive outcome, since several studies have shown that the FNS correctly forecasts responses to new foods (Siegrist, Hartmann, \& Keller, 2013; Sogari, Menozzi, \& Mora, 2019; Verbeke, 2015). Previous studies on FNS and foods made with upcycled ingredients reached different conclusions. Coderoni and Perito (2020) reported that FNS negatively correlated with purchase intentions, while the willingness to try foods made with olive oil by-products had a significant negative correlation with technophobia but not with neophobia in Perito et al. (2019).

Price was the attribute that mostly affected consumers' WTP followed by the Carbon Trust label, protein and finally information on the type of flour. These results are in accordance with other studies where positive consumers' preferences towards the carbon footprint label (Echeverría, Hugo Moreira, Sepúlveda, \& Wittwer, 2014) and nutrition claim on proteins (Van Wezemael, Caputo, Nayga Jr, Chryssochoidis, \& Verbeke, 2014) were found. Since "price”, "protein" and "Carbon" were all more important to consumers than the ingredients used (i.e. "flour"), consumer acceptance of foods with upcycled ingredients could be shaped by promoting these foods with a lower price, with the Carbon Trust label and with appropriate nutrition protein claims.

On average, consumers preferred biscuits made with conventional (i.e., wheat) flour and tended to reject biscuits made with upcycled sunflower flour. However, we found significant consumers' 
heterogeneity with three different groups of consumers identified. The "environmentalist" group

had the lowest rejection towards upcycled sunflower flour in biscuits and the strongest preference

for the protein claim and the Carbon Trust label. This group might therefore be the most suitable to target the marketing and promotional strategies for the launch of the new biscuits made with upcycled ingredients, as it has been reported that a strong environmental consciousness can lead towards more sustainable lifestyle choices (Truelove \& Parks, 2012).

This manuscript has two main limitations. Firstly, the sample size is small which could limit the representativeness of our findings. Secondly, being this a hypothetical study, it might suffer from hypothetical bias which could have affected the estimation of consumers' WTP. Although this study was anonymous and a cheap talk was used to limit hypothetical bias effect, it is also possible that social desirability bias might have influenced consumers' responses. Preferences for the Carbon Trust label might have been due to this label being more known to consumers compared to the concept of upcycled ingredients.

Appropriate consumer-friendly definitions and labelling for upcycled ingredients need to be developed and suitably communicated before these new products are launched on the market. Indeed, in the food context, there have been many examples that reflect how the name of a dish, a food product or a label affect consumers' perceptions (Irmak, Vallen, \& Robinson, 2011; Kunst \& Hohle, 2016). Further work also needs to be conducted to find the most suitable way to communicate the nutritional and environmental advantages of upcycled ingredients to consumers. It is possible that increasing consumer familiarity with the concept and benefits of upcycled ingredients will improve the acceptability of new foods made with such by-products and this hypothesis should be tested in future studies. In general, exposure has been reported to be an important driver of acceptance and should be an element to secure new product acceptance 
alongside with taste (Lease, MacDonald, \& Cox, 2014). Other studies on consumers' preferences towards food by-products also concluded that appropriate definitions, information on benefits and marketing strategies are key to success (Aschemann-Witzel \& Peschel, 2019; Bhatt et al., 2018; Coderoni \& Perito, 2020; Perito et al., 2019).

In addition to communicating information on upcycled ingredients to consumers, there are further areas to explore. While currently there are no specific regulations concerning foods made with byproducts, many regulatory challenges are likely to affect the sale of upcycled ingredients in Europe. Some upcycled ingredients might in fact be considered novel foods, because they were not produced or used in the EU before 1997, and might need to be authorized by the European Food Safety Authority (EFSA) before entering the EU market (EFSA, 2016). It would be important for the regulatory authorities to consider the environmental and nutritional benefits of upcycled ingredients in order to allow for procedures that would simplify their entrance into the market and make a positive impact on our societies. This would in turn encourage food ingredient manufacturers to invest in the development of upcycled ingredients and offer more cost-effective options to food manufacturers for the development of healthier and more sustainable foods.

Future research should include the replication of this study using larger samples of UK consumers and in other countries, the use of different food products and testing the effect of different message framing information (i.e., private and public benefits of using upcycled ingredients) about upcycled ingredients to consumers. In addition, future studies should include sensory tests of these new products as it is well known in the literature that sensory attributes are key drivers of consumers' preferences (Asioli et al., 2017; Grunert, 2005; Lima, de Alcantara, Ares, \& Deliza, 2019). Sensory testing of foods with upcycled ingredients could therefore provide further realistic valuable consumer insights into this topic. It is also recommended to carry out real experiments using real 
products in the field, in supermarkets, using real choice experiments (RCE) or experimental auctions which will provide further external validity of these results (Alfnes \& Rickertsen, 2011;

Lusk \& Shogren, 2007).

Finally, a multidisciplinary effort bringing together regulators, new product developers, food manufacturers and marketers will be needed to ensure that foods with upcycled ingredients can enter the food market and find a stable position on the supermarket's shelf.

\section{ACKNOWLEDGMENTS}

This research was funded by a Food Pump Priming Awards from the Research Dean for Food at the University of Reading, grant number E3630500.

\section{TRASPARENT REPORTING}

Questionnaire, data, analysis codes and other supplements are available on request, while preregistration of the study is available in https://aspredicted.org/blind.php? $\mathrm{x}=\mathrm{z} 7 \mathrm{cy} 6 \mathrm{~b}$.

\section{REFERENCES}

Agovino, M., Cerciello, M., \& Gatto, A. (2018). Policy efficiency in the field of food sustainability. The adjusted food agriculture and nutrition index. Journal of environmental management, 218, 220-233.

Alfnes, F., \& Rickertsen, K. (2011). Non-market valuation: experimental methods. The Oxford Handbook of the economics of food consumption and policy, 215, 242.

Aschemann-Witzel, J., \& Peschel, A. O. (2019). How circular will you eat? The sustainability challenge in food and consumer reaction to either waste-to-value or yet underused novel ingredients in food. Food Quality and Preference, 77, 15-20.

Asioli, Næs, T., Granli, B. S., \& Lengard Almli, V. (2014). Consumer preferences for iced coffee determined by conjoint analysis: an exploratory study with Norwegian consumers. International Journal of Food Science \& Technology, 49(6), 1565-1571.

Asioli, Næs, T., Øvrum, A., \& Almli, V. L. (2016). Comparison of rating-based and choice-based conjoint analysis models. A case study based on preferences for iced coffee in Norway. Food Quality and Preference, 48, 174-184.

Asioli, Varela, P., Hersleth, M., Almli, V. L., Olsen, N. V., \& Næs, T. (2017). A discussion of recent methodologies for combining sensory and extrinsic product properties in consumer 
studies. Food Quality and Preference, 56, 266-273.

Augustin, M. A., Sanguansri, L., Fox, E. M., Cobiac, L., \& Cole, M. B. (2020). Recovery of wasted fruit and vegetables for improving sustainable diets. Trends in Food Science \& Technology, 95, 75-85.

Banovic, M., Arvola, A., Pennanen, K., Duta, D. E., Brückner-Gühmann, M., Lähteenmäki, L., et al. (2018). Foods with increased protein content: A qualitative study on European consumer preferences and perceptions. Appetite, 125, 233-243.

Barba, F. J., Zhu, Z., Koubaa, M., Sant'Ana, A. S., \& Orlien, V. (2016). Green alternative methods for the extraction of antioxidant bioactive compounds from winery wastes and by-products: A review. Trends in Food Science \& Technology, 49, 96-109.

BBC. (2019). Food waste news. https://www.bbc.co.uk/news/topics/cr58gnj8zzxt/food-waste.

Bhat, C. R. (1997). An endogenous segmentation mode choice model with an application to intercity travel. Transportation science, 31(1), 34-48.

Bhatt, S., Lee, J., Deutsch, J., Ayaz, H., Fulton, B., \& Suri, R. (2018). From food waste to value- added surplus products (VASP): Consumer acceptance of a novel food product category. Journal of Consumer Behaviour, 17(1), 57-63.

Coderoni, S., \& Perito, M. A. (2020). Sustainable consumption in the circular economy. An analysis of consumers' purchase intentions for waste-to-value food. Journal of Cleaner Production, 252, 119870.

Cummings, R. G., \& Taylor, L. O. (1999). Unbiased value estimates for environmental goods: a cheap talk design for the contingent valuation method. American economic review, 89(3), 649-665.

Echeverría, R., Hugo Moreira, V., Sepúlveda, C., \& Wittwer, C. (2014). Willingness to pay for carbon footprint on foods. British Food Journal, 116(2), 186-196.

EFSA. (2012). EU Register on nutrition and health claims. In.

EFSA. (2016). Guidance on the preparation and presentation of an application for authorisation of a novel food in the context of Regulation (EU) 2015/2283. EFSA Journal, 14(11), e04594.

FAO. (2011). Global Food Losses and Food Waste - Extent, Causes and Prevention. . FAO: Rome, Italy.

FAO. (2015). Global initiative on food loss and waste reduction. Key facts on food loss and waste you should know, 01-02.

Fastcompany. (2019). Everything you need to know about the booming business of fighting food waste. https://www.fastcompany.com/90337075/inside-the-booming-business-of-fightingfood-waste.

Food Business News. (2019). "Upcycled" ingredients gain traction. https://www.foodbusinessnews.net/articles/13372-upcycled-ingredients-gain-traction.

Food Navigator USA. (2018). Upcycling: 'We believe there is a second life for everything', says Rise CEO. https://www.foodnavigator-usa.com/Article/2018/08/16/Upcycling-We-believethere-is-a-second-life-for-everything-says-Rise-CEO.

Galanakis, C. M. (2012). Recovery of high added-value components from food wastes: conventional, emerging technologies and commercialized applications. Trends in Food Science \& Technology, 26(2), 68-87.

Galanakis, C. M. (2013). Emerging technologies for the production of nutraceuticals from agricultural by-products: A viewpoint of opportunities and challenges. Food and Bioproducts Processing, 91(4), 575-579.

Garcia-Garcia, G., Stone, J., \& Rahimifard, S. (2019). Opportunities for waste valorisation in the food industry-A case study with four UK food manufacturers. Journal of Cleaner Production, 211, 1339-1356.

Gómez, M., \& Martinez, M. M. (2018). Fruit and vegetable by-products as novel ingredients to 

nutrition, 58(13), 2119-2135.

Grasso, S., Liu, S., \& Methven, L. (2020). Quality of muffins enriched with upcycled defatted sunflower seed flour. $L W T, 119,108893$.

Grasso, S., Omoarukhe, E., Wen, X., Papoutsis, K., \& Methven, L. (2019). The use of upcycled defatted sunflower seed flour as a functional ingredient in biscuits. Foods, 8(8), 305.

Greene, W. H., \& Hensher, D. A. (2003). A latent class model for discrete choice analysis: contrasts with mixed logit. Transportation Research Part B: Methodological, 37(8), 681698.

Grunert, K. G. (2005). Food quality and safety: consumer perception and demand. European review of agricultural economics, 32(3), 369-391.

Hagman, L., Eklund, M., \& Svensson, N. (2019). Assessment of By-product Valorisation in a Swedish Wheat-Based Biorefinery. Waste and Biomass Valorization.

Helkar, P. B., Sahoo, A., \& Patil, N. (2016). Review: Food industry by-products used as a functional food ingredients. International Journal of Waste Resources, 6(3), 1-6.

Hensher, D. A., Rose, J. M., \& Greene, W. H. (2005). Applied choice analysis: a primer: Cambridge University Press.

Hess, S., Ben-Akiva, M., Gopinath, D., \& Walker, J. (2011). Advantages of latent class over continuous mixture of logit models. Institute for Transport Studies, University of Leeds. Working paper.

Hole, A. R. (2007). Fitting mixed logit models by using maximum simulated likelihood. The Stata Journal, 7(3), 388-401.

Irmak, C., Vallen, B., \& Robinson, S. R. (2011). The impact of product name on dieters' and nondieters' food evaluations and consumption. Journal of Consumer Research, 38(2), 390405.

Jaeger, S. R. (2006). Non-sensory factors in sensory science research. Food Quality and Preference, 17(1-2), 132-144.

Kroyer, G. T. (1995). Impact of food processing on the environment - an overview. LWT - Food Science and Technology, 28(6), 547-552.

Kunst, J. R., \& Hohle, S. M. (2016). Meat eaters by dissociation: How we present, prepare and talk about meat increases willingness to eat meat by reducing empathy and disgust. Appetite, 105, 758-774.

Lease, H., MacDonald, D. H., \& Cox, D. (2014). Consumers' acceptance of recycled water in meat products: The influence of tasting, attitudes and values on hedonic and emotional reactions. Food Quality and Preference, 37, 35-44.

Lima, M., de Alcantara, M., Ares, G., \& Deliza, R. (2019). It is not all about information! Sensory experience overrides the impact of nutrition information on consumers' choice of sugarreduced drinks. Food Quality and Preference, 74, 1-9.

Louviere, J. J., Hensher, D. A., \& Swait, J. D. (2000). Stated choice methods: analysis and applications: Cambridge university press.

Lusk, J. L., \& Briggeman, B. C. (2009). Food Values. American Journal of Agricultural Economics, 91(1), 184-196.

Lusk, J. L., \& Shogren, J. F. (2007). Experimental auctions: Methods and applications in economic and marketing research: Cambridge University Press.

Manchuliantsau, A., \& Tkacheva, A. (2019). Upcycling solid food wastes and by-products into human consumption products. In: Google Patents.

Martin, M., \& Parsapour, A. (2012). Upcycling wastes with biogas production: : An exergy and economic analysis. In, Venice 2012: International Symposium on Energy from Biomass and Waste. Venice, Italy. 
Mirzaei-Aghsaghali, A., \& Maheri-Sis, N. (2008). Nutritive value of some agro-industrial byproducts for ruminants-A review. World J. Zool, 3(2), 40-46.

Molina-Alcaide, E., \& Yáñez-Ruiz, D. R. (2008). Potential use of olive by-products in ruminant feeding: A review. Animal Feed Science and Technology, 147(1-3), 247-264.

Office for National Statistics. (2019). Estimates of the population for the UK, England and Wales, Scotland and Northern Ireland. In: ONS Lodon.

Øvrum, A., Alfnes, F., Almli, V. L., \& Rickertsen, K. (2012). Health information and diet choices: Results from a cheese experiment. Food Policy, 37(5), 520-529.

Pacifico, D., \& Yoo, H. I. (2013). lclogit: A Stata command for fitting latent-class conditional logit models via the expectation-maximization algorithm. The Stata Journal, 13(3), 625-639.

Parfitt, J., Barthel, M., \& Macnaughton, S. (2010). Food waste within food supply chains: quantification and potential for change to 2050. Philosophical transactions of the royal society B: biological sciences, 365(1554), 3065-3081.

Perito, M. A., Di Fonzo, A., Sansone, M., \& Russo, C. (2019). Consumer acceptance of food obtained from olive by-products. British Food Journal.

Pliner, P., \& Hobden, K. (1992). Development of a scale to measure the trait of food neophobia in humans. Appetite, 19(2), 105-120.

Reimers, H., \& Hoffmann, S. (2019). Transparent Price Labelling for Sustainable Products: A Boost for Consumers' Willingness to Buy? Marketing ZFP, 41(2), 21-36.

Roth, M., Jekle, M., \& Becker, T. (2019). Opportunities for Upcycling Cereal Byproducts with Special Focus on Distiller's Grains. Trends in Food Science \& Technology.

Shen, J. (2009). Latent class model or mixed logit model? A comparison by transport mode choice data. Applied Economics, 41(22), 2915-2924.

Shogren, J. F. (2011). The Oxford handbook of the economics of food consumption and policy: Oxford University Press.

Siegrist, M., Hartmann, C., \& Keller, C. (2013). Antecedents of food neophobia and its association with eating behavior and food choices. Food Quality and Preference, 30(2), 293-298.

SkyNews. (2019). Tesco, Sainsbury's, Waitrose and Nestle to halve food waste by 2030. https://news.sky.com/story/tesco-sainsburys-waitrose-and-nestle-to-halve-food-waste-by2030-11718820.

Sogari, G., Menozzi, D., \& Mora, C. (2019). The food neophobia scale and young adults' intention to eat insect products. International Journal of Consumer Studies, 43(1), 68-76.

Spinelli, S., Padalino, L., Costa, C., Del Nobile, M. A., \& Conte, A. (2019). Food by-products to fortified pasta: A new approach for optimization. Journal of Cleaner Production, 215, 985991.

Steenhuis, I. H. M., Waterlander, W. E., \& de Mul, A. (2011). Consumer food choices: the role of price and pricing strategies. Public Health Nutrition, 14(12), 2220-2226.

Stenmarck, Å., Jensen, C., Quested, T., Moates, G., Buksti, M., Cseh, B., et al. (2016). Estimates of European food waste levels.-FUSIONS: Reducing food waste through social innovation, Stockholm. In: on-line.

Train, K. E. (2008). EM algorithms for nonparametric estimation of mixing distributions. Journal of Choice Modelling, 1(1), 40-69.

Train, K. E. (2009). Discrete choice methods with simulation: Cambridge university press.

Trigo, J. P., Alexandre, E. M., Saraiva, J. A., \& Pintado, M. E. (2019). High value-added compounds from fruit and vegetable by-products-Characterization, bioactivities, and application in the development of novel food products. Critical reviews in food science and nutrition, 1-29.

Truelove, H. B., \& Parks, C. (2012). Perceptions of behaviors that cause and mitigate global warming and intentions to perform these behaviors. Journal of Environmental Psychology, 
32(3), 246-259.

Turksoy, S., \& Özkaya, B. (2011). Pumpkin and carrot pomace powders as a source of dietary fiber and their effects on the mixing properties of wheat flour dough and cookie quality. Food Science and Technology Research, 17(6), 545-553.

Van Wezemael, L., Caputo, V., Nayga Jr, R. M., Chryssochoidis, G., \& Verbeke, W. (2014). European consumer preferences for beef with nutrition and health claims: A multi-country investigation using discrete choice experiments. Food Policy, 44, 167-176.

Vega-Zamora, M., Torres-Ruiz, F. J., \& Parras-Rosa, M. (2019). Towards sustainable consumption: Keys to communication for improving trust in organic foods. Journal of Cleaner Production, 216, 511-519.

Verbeke, W. (2015). Profiling consumers who are ready to adopt insects as a meat substitute in a Western society. Food Quality and Preference, 39, 147-155.

WRAP. (2017). Courtauld 2025 signatory data report: 2015 and 2016. In. Banbury.

Yoo, H. I. (2019). lclogit2: An enhanced module to estimate latent class conditional logit models. Available at SSRN 3484429. 


\section{Declaration of interests}

$\bigotimes$ The authors declare that they have no known competing financial interests or personal relationships that could have appeared to influence the work reported in this paper.

$\square$ The authors declare the following financial interests/personal relationships which may be considered as potential competing interests:

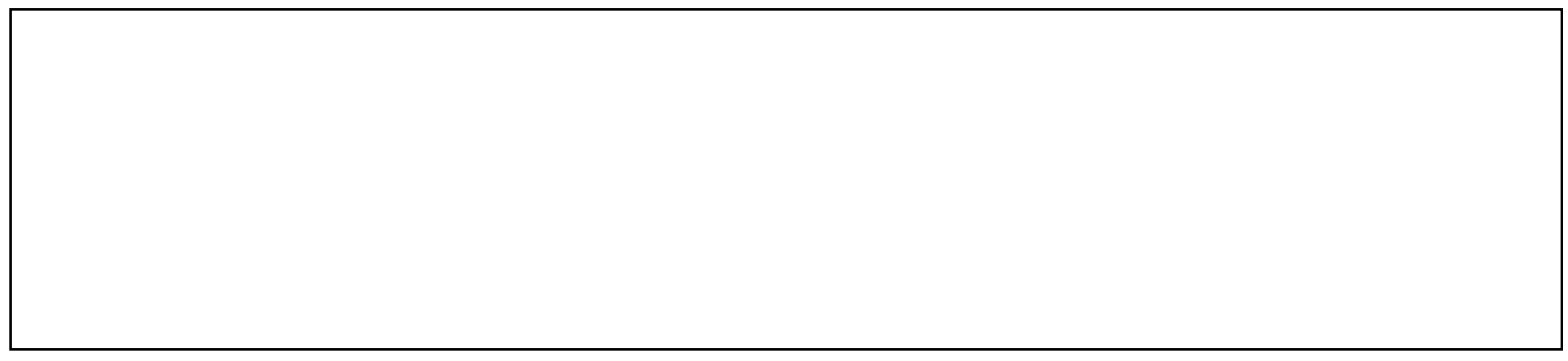

